\title{
Direitos Humanos LGBTIs e Sistema de Justiça: Standards de Proteção e Atuação do Poder Judiciário e do Ministério Público
}

\section{Roger Raupp Rios}

Doutorado em Direito (2004), Mestrado em Direito (2000) e Graduação em Direito (1993) pela Universidade Federal do Rio Grande do Sul. Professor do Programa de Pós-Graduação em Direito da Unisinos - Mestrado e Doutorado e do PPG Mestrado Profissional Enfam. Desembargador Federal do Tribunal Regional Federal da 4ạ Região. Tem experiência na área de Direito, com ênfase em Direito Público, atuando principalmente nos seguintes temas: direitos humanos, direitos fundamentais, direito da antidiscriminação, direitos sexuais e direito à saúde. http://lattes.cnpq.br/9032766713121501. https://orcid.org/0000-0002-5105-3861.roger.raupp.rios@gmail.com

\section{RESUMO}

O artigo trata do sistema de justiça e da proteção dos direitos humanos das pessoas LGBTIs, sustentando que tal tarefa integra os deveres institucionais do sistema de justiça e salientando o efeito benéfico do cumprimento desta tarefa às instituições de justiça. $O$ texto estrutura-se em duas partes, elaboradas a partir de revisão de normas legais e literatura especializada. Na primeira parte tomam-se os standards do sistema universal e do sistema interamericano de direitos humanos sobre os direitos LGBTIs. Na segunda parte, são consideradas as consequências jurídicas e institucionais desses standards para os ordenamentos jurídicos nacionais, bem como os efeitos salutares à legitimidade democrática e ao aperfeiçoamento da atividade dos órgãos e atores do sistema de justiça. Conclui-se que a legitimidade democrática de um ordenamento jurídico e a qualidade de um sistema de justiça, podem ser medidas de acordo com o grau de conhecimento e de compromisso que suas instituições e integrantes têm diante dos direitos humanos universais de indivíduos e grupos discriminados.

Palavras-chave: Direitos LGBTIs. Sistemas de justiça. Não discriminação. Direitos humanos.

HUMAN RIGHTS STANDARDS AND LGBTI RIGHTS IN THE LEGAL SYSTEM

ABSTRACT

The article addresses the justice system and the protection of LGBTI human rights, arguing that this is a task of the justice system institutional duties, and highlighting the beneficial effect of fulfilling such task. Taken into account the legal framework and academic knowledge, it has two parts. In the first part, it deals with the human rights standards of the universal system and the inter-American system on LGBTI rights. In the second part, it considers the legal and institutional consequences of these standards for national legal systems, as well as the salutary impact on democratic legitimacy and to the improvement of work of the organs and actors of the justice system. It concludes that the democratic legitimacy of a legal system, as well as the quality of a justice system, can be measured according to the degree of knowledge and commitment that its institutions and members have regarding the universal human rights of discriminated individuals and groups.

Keywords: LGBTI rights. Legal systems. Non-discrimination. Human rights.

1 Introdução. 2 Direitos humanos e direitos LGBTIs. 2.1 Os direitos humanos LGBTIs no sistema universal de direitos humanos. 2.2 Os direitos humanos LGBTIs no sistema interamericano de direitos humanos. 3 Os direitos humanos LGBTIs e os sistemas de justiça nacionais. 3.1 Os direitos humanos LGBTIs e os ordenamentos jurídicos nacionais. 3.2 Direitos humanos LGBTIs e sistema de justiça nacional. 4 Considerações finais. 5 Referências. 


\section{Humanos e \\ Democracia}

\section{INTRODUÇÃO}

Esta reflexão cuida da tarefa do sistema de justiça diante da proteção dos direitos humanos das pessoas LGBTIs, ${ }^{1}$ mediante duas proposições: (1) tal proteção integra os deveres institucionais do Poder Judiciário e do Ministério Público, dado que suas atribuições constitucionais implicam o respeito, a garantia e a efetividade dos direitos humanos universais de forma integral, e (2) o efeito benéfico para as instituições de justiça, no constitucionalismo democrático, decorre do cumprimento desta tarefa.

Para tanto, o estudo estrutura-se em duas partes. Na primeira parte tomam-se os standards do sistema universal e do sistema interamericano de direitos humanos sobre os direitos LGBTIs como concretizações dos direitos humanos universais e gerais. Na segunda parte são consideradas as consequências jurídicas e institucionais destes standards para os ordenamentos jurídicos nacionais, bem como os efeitos salutares para a legitimidade democrática e para o aperfeiçoamento da atividade dos órgãos e atores do sistema de justiça.

\section{DIREITOS HUMANOS E DIREITOS LGBTIS}

A teoria e a prática dos direitos humanos internacionais na quadra histórica em que vivemos, não deixam dúvidas quanto à sua pertinência e à sua necessidade diante das realidades experimentadas por indivíduos e grupos LGBTI. A formulação de standards de proteção de direitos humanos universais ameaçados ou violados por motivo de Orientação Sexual e de Identidade de Gênero (Osig), associada à atuação de órgãos universais e regionais dos respectivos sistemas internacionais de direitos humanos, dão testemunhos inequívocos desse desenvolvimento. Esta trajetória, longe de se restringir a afirmações de direito internacional público, desborda na evolução do direito constitucional dos direitos fundamentais das nações democráticas, com consequências diretas e concretas para os agentes dos sistemas de justiça nacionais.

\subsection{Os direitos humanos LGBTIs no sistema universal de direitos humanos}

Os direitos humanos universais, como concebidos no contexto histórico que se seguiu à Segunda Guerra Mundial, expressam aspirações políticas e projetos jurídicos. Com efeito, se politicamente decorrem da necessidade de uma ordem internacional que ponha freios a regimes políticos nacionais, em que a guerra externa e a tirania interna nutrem-se mutuamente (BEITZ, 2012), juridicamente a ideia de direitos humanos irmana-se ao constitucionalismo democrático caracterizado pela força normativa dos direitos fundamentais (HESSE, 1991).

Nessa quadra, diante de propostas e de projetos tão abrangentes, conceitual e globalmente, não é de se estranhar que a formulação dos direitos humanos tenha adotado parâmetros abstratos e universalistas. Inaugurado pela Declaração Universal dos Direitos Humanos de 1948, e complementado pelos Pactos Internacionais de Direitos Civis e Políticos e de Direi-

\footnotetext{
“LGBTI é a sigla para 'lésbicas, gays, bissexuais, transgêneros e intersexo'. Embora esses termos tenham cada vez mais ressonância global, em diferentes culturas outros termos podem ser utilizados para descrever pessoas que se sentem atraídas por pessoas do mesmo gênero, pessoas cuja identidade de gênero se diferencia do sexo designado ao nascimento, pessoas que apresentam identidades de gênero não binárias e pessoas cujas características sexuais não se encaixam nas típicas definições de macho e fêmea" (ONU, 2018a).
} 
tos Econômicos, Sociais e Culturais (ambos de 1966), o "corpus juris" do direito internacional dos direitos humanos foi desafiado pela concretude das experiências de ameaças e violações. Daí a crescente especificação das normativas internacionais de direitos humanos (PIOVESAN, 2010, p. 44), que ganharam paulatina concretização quanto aos sujeitos protegidos e, ao mesmo tempo, densidade jurídica. A promulgação das Convenções Internacionais sobre todas as formas de discriminação racial (1965), de discriminação contra a mulher (1979), sobre os direitos das crianças (1989), Convenção Interamericana sobre os direitos das pessoas idosas (2015) e Convenção Internacional sobre os direitos das pessoas com deficiência (2006), atestam esse fenômeno de especificação subjetiva e força jurídica. Ainda que se ressentindo da mesma intensidade normativa, outras declarações também avançaram, alcançando, por exemplo, os direitos dos povos indígenas (2007). Em todos os casos, onde a distinção entre diplomas "hard law" e "soft law" decorre do jogo intrincado da política global e da complexa dinâmica das instituições internacionais, o que se verifica é o esforço rumo a padrões civilizatórios mais robustos diante do pluralismo e da diversidade em busca do convívio pacífico e respeitoso.

$\mathrm{Na}$ esfera da sexualidade, encontram-se semelhantes trajetórias, desafios e urgências. A par da proclamação universalista e abstrata dos direitos humanos, é preciso concretizá-los e efetivá-los em esferas e âmbitos da vida decisivos para o respeito à dignidade humana, que tocam desde as relações mais íntimas e privadas até políticas estatais e relações intersubjetivas e coletividades na esfera pública.

Um rápido escorço histórico dos direitos LGBTIs registra seus primeiros passos a partir do reconhecimento da situação de vulnerabilidade das mulheres, com a ideia de direitos reprodutivos (CABAL; ROA; LEMAITRE, 2001). Com efeito, após as proclamações genéricas e abstratas relativas ao direito à vida, à saúde, à igualdade e não discriminação, à integridade corporal e à proteção contra violência, ao trabalho e à educação (inscritos na Declaração Universal dos Direitos Humanos, no Pacto Internacional de Direitos Civis e Políticos, no Pacto Internacional dos Direitos Econômicos, Sociais e Culturais e na Convenção Americana de Direitos Humanos), sucederam-se documentos internacionais e conferências preocupadas especificamente com a reprodução e, neste contexto, a condição feminina.

Daí que a Primeira Conferência Internacional de Direitos Humanos (Teerã-1968) reconheceu a importância dos direitos humanos da mulher e decidiu pela necessidade de medidas para promovê-los (artigo 15). A Assembleia Geral das Nações Unidas declarou 1975 o Ano Internacional da Mulher, bem como estabeleceu o decênio 1976-1985 especialmente voltado para a melhoria da condição das mulheres, realizando, dentro deste período, duas conferências mundiais: 1980 em Copenhagen e 1985 em Nairobi. Antes destas datas, em 1979 é promulgada a importante Convenção sobre a Eliminação de Todas as Formas de Discriminação contra a Mulher.

Em 1993, a Conferência Mundial de Direitos Humanos, realizada em Viena, declarou que os direitos humanos das mulheres são parte inalienável, integral e indivisível dos direitos humanos, sendo dever sua participação em igualdade de condições sociais e a erradicação de todas as formas de discriminação baseadas no sexo e de todas as formas de violência contra a mulher. 


\section{Humanos e \\ Democracia}

Em 1994, a Conferência Mundial sobre População e Desenvolvimento (Cairo) estabeleceu um programa de ação que afirmou os direitos reprodutivos como categoria de direitos humanos já reconhecidos em tratados internacionais, incluindo o direito à escolha livre e responsável do número de filhos e de seu espaçamento, dispondo da informação, educação e meios necessários para tanto. Foi importante para os fins deste estudo a declaração de que a saúde reprodutiva implica a capacidade de desfrutar de uma vida sexual satisfatória e sem riscos. O documento, como um todo, reafirma a importância de relações de gênero mais igualitárias, com maior liberdade para a mulher, livre de discriminação e violência. É relevante também a menção ao direito de homens, mulheres e adolescentes de obter informação e ter acesso a métodos seguros, eficazes, aceitáveis e de sua eleição para a regulação da fecundidade.

Desta conferência decorreu o Plano de Ação do Cairo, que, além de introduzir o conceito de direitos reprodutivos, sinalizou para o reconhecimento de direitos sexuais, destacando o direito de exercer a sexualidade e a reprodução livre de discriminações, coerções e violências; na mesma oportunidade, também foi assentado que os Estados-Partes, além de estimularem e promoverem o relacionamento respeitoso e igualitário entre homens e mulheres, devem atentar para as necessidades dos adolescentes, capacitando-os a melhor decidir sobre o exercício de sua sexualidade e dedicar atenção especial a segmentos populacionais mais vulneráveis às violações de direitos humanos nos campos da reprodução e da sexualidade.

Em 1995, a Quarta Conferência Mundial da Mulher foi realizada em Pequim, confirmando as diretrizes definidas no Cairo. Nela, reforçou-se a necessidade da proteção dos direitos estreitamente ligados aos direitos reprodutivos, tais como direitos sexuais, direito à saúde, à integridade, à proteção contra a violência, à igualdade e não discriminação, matrimônio, educação e proteção contra exploração sexual. É importante salientar que a Plataforma de Pequim, no capítulo "Mulher e Saúde", cuidou de questões fundamentais, como o reconhecimento de direitos sexuais e reprodutivos, afirmando o direito ao livre-exercício da sexualidade, por meio, principalmente, da ênfase na saúde sexual. ${ }^{2}$

Nesse apanhado histórico, é de ressaltar-se que a sexualidade foi abordada nos instrumentos internacionais a partir da legítima e necessária preocupação com a situação da muIher, engendrada desde o espectro dos direitos reprodutivos e da noção de direitos sexuais, que, todavia, nesta perspectiva, requer afirmação mais firme e desenvolvimento autônomo, rumo à ideia de um direito da sexualidade (RIOS, 2006; BORRILLO, 2009).

\footnotetext{
Reza o item 30 da Declaração da Conferência Mundial sobre a Mulher: "Assegurar a igualdade de acesso e a igualdade de tratamento de mulheres e homens na educação e saúde e promover a saúde sexual e reprodutiva das mulheres e sua educação." Por sua vez, o item 97 da Plataforma de Ação traz: "os direitos humanos da mulher incluem seu direito a ter controle sobre aspectos relativos à sexualidade, incluída sua saúde sexual e reprodutiva, e decidir livremente a respeito destas questões, sem estarem sujeitas à coerção, discriminação ou violência. As relações sexuais e a reprodução, incluindo o respeito à integridade da pessoa, exigem o respeito e o consentimento recíprocos e a vontade de assumir conjuntamente a responsabilidade quanto a consequências do comportamento sexual."
} 
A afirmação dos "direitos LGBTIs" vem encontrando progressos e resistências no sistema universal de direitos humanos (NAGAMINE, 2019). De fato, ao lado da denúncia institucional explícita sobre execuções extrajudiciais, sumárias e arbitrárias, ${ }^{3}$ como também práticas de tortura e maus tratos, ${ }^{4}$ relacionadas à "orientação sexual ${ }^{5}$ e à identidade de gênero" (Osig), o reconhecimento da gravidade das violações dos direitos humanos LGBTIs tem gerado iniciativas no Conselho de Direitos Humanos da ONU, materializados em relatórios e mandatos de trabalho, tais como a Resolução 17/19 (ONU, 2011a). Desse modo, mesmo que a oposição de determinados países restrinja uma manifestação institucional mais vigorosa quanto às violações de direitos humanos motivadas na Osig, sua urgência e legitimidade mais e mais se consolidam.

\footnotetext{
3 Reproduzo, conforme referências em ONU (2012, p. 13-14): "Documentación sobre asesinatos extrajudiciales de personas LGBT: Observaciones finales del Comité de Derechos Humanos respecto de Polonia (CCPR/CO/82/POL), párr. 18, y El Salvador (CCPR/ CO/78/SLV), párr. 16; Informe de la Relatora Especial sobre ejecuciones extrajudiciales, sumarias o arbitrarias sobre su misión a México (E/CN.4/2000/3/Add.3), párrs. 91 a 92; Informe de la Relatora Especialsobre ejecuciones extrajudiciales, sumarias o arbitrarias sobre su misión a El Salvador (A/HRC/17/26/ Add.2), párr. 28; Informe de la Relatora Especial sobre la situación de los defensores de los derechos humanos sobre su misión a Colombia (A/HRC/13/22/Add.3), párr. 50; Informe de la Relatora Especial sobre ejecuciones extrajudiciales, sumarias o arbitrarias (A/HRC/14/24/Add.2), párr. 74; Observaciones finales del Comité para la Eliminación de la Discriminación contra la Mujer (CEDAW/C/ZAF/CO/4), párr. 39. Asesinato de personas transgénero: Informes de la Relatora Especial sobre ejecuciones extrajudiciales, sumarias o arbitrarias: E/CN.4/2000/3, párr. 54 ("trabajador sexual travestista" en el Brasil); E/CN.4/2001/9, párr. 49 (travestista asesinado a disparos en El Salvador); E/CN.4/2003/3/ Add.2, párr. 68 (trabajador transgénero aparentemente asesinado detrás de la catedral de San Pedro Sula); E/CN.4/2003/3, párr. 66 (asesinato de tres personas transgénero en Venezuela sin que el Gobierno iniciara una investigación)".

4 Reproduzo, conforme referência da ONU (2012, p. 22-14): "Observaciones finales del Comité de Derechos Humanos respecto de los Estados Unidos de América (CCPR/C/USA/CO/3) párr. 25; Observaciones finales del Comité contra la Tortura respecto de los Es- tados Unidos de América (CAT/C/USA/CO/2), párrs. 32 y 37; Ecuador (CAT/C/ECU/ $\mathrm{CO} / 3$ ), párr. 17; Argentina (CAT/C/CR/33/1), párr. 6 g); Egipto (CAT/C/CR/29/4), párr. 5 e); Comité contra la Tortura, Observación general No. 2, párr. 21 [Ref: HRI/GEN/1/Rev.9(Vol.II)]; véanse también las observaciones finales del Comité respecto del Ecuador (CAT/C/ECU/CO/3), párr. 17; Argentina (CAT/C/CR/33/1), párr. 6; y Brasil (A/56/44), párr. 119. (...) Informes del Relator Especial sobre la cuestión de la tortura y otros tratos o penas crueles, inhumanos o degradantes: E/CN.4/2001/66/Add.2, párrafo 199; E/CN.4/2005/62/Add.1, párrafos 1019 y 1161; E/CN.4/2004/56/ Add.1, párrafo 1327; E/CN.4/2003/68/Add.1, párrafos 446, 463 a 465 y 1861; E/CN.4/2002/76/Add.1, párrafos 16, 507 y 508, 829 y 1709 a 1716; E/CN.4/2001/66, párrafo 1171; E/CN.4/2000/9, párrafos 145, 151, y 726; E/CN.4/1995/34, párrafo 614."

5 Compreendemos orientação sexual como uma referência à capacidade de cada pessoa de ter uma profunda atração emocional, afetiva ou sexual por indivíduos de gênero diferente, do mesmo gênero ou de mais de um gênero, assim como ter relações íntimas e sexuais com essas pessoas (PRINCÍPIOS DE YOGYAKARTA, 2017).

6 Compreendemos identidade de gênero a profundamente sentida experiência interna e individual do gênero de cada pessoa, que pode ou não corresponder ao sexo atribuído no nascimento, incluindo o senso pessoal do corpo (que pode envolver, por livre escolha, modificação da aparência ou função corporal por meios médicos, cirúrgicos ou outros) e outras expressões de gênero, inclusive vestimenta, modo de falar e maneirismos. (PRINCÍPIOS DE YOGYAKARTA, 2017).
} 


\section{Democracia}

Ainda no sistema universal de direitos humanos, é importante indicar, além da importante decisão do Conselho de Direitos Humanos no caso Toonen, ${ }^{7}$ o informe do Alto Comissariado para os Direitos Humanos realizado em conformidade com a referida Resolução 17/19 (ONU, 2011b), bem como as manifestações de diversos órgãos do sistema universal que ressaltam as violações a direitos humanos LGBTIs. ${ }^{8}$

Ainda no âmbito do sistema universal, a campanha internacional pelo respeito aos direitos humanos de pessoas LGBTIs desdobrou-se na explicitação de padrões frequentes de violações de direitos e na elaboração de standards para sua proteção, assim sintetizados (ONU, 2018b):

a. enumeração das formas mais comuns de violações: agressões violentas, físicas e verbais; normas penais discriminatórias; restrições arbitrárias ao exercício dos direitos; tratamento discriminatório em diversos âmbitos.

b. Obrigações jurídicas básicas: proteger as pessoas da violência homofóbica; revogar legislação discriminatória; proibir discriminação homofóbica; salvaguardar a liberdade de expressão e o exercício dos direitos.

Ao finalizar essa breve notícia dos direitos humanos internacionais no sistema universal, é importante registrar os "Princípios sobre a aplicação da legislação internacional de direitos humanos em relação à orientação sexual e identidade de gênero", conhecidos como "Princípios de Yogyakarta" (2017). Fruto do trabalho de um grupo de especialistas mundialmente conhecidos, ali se oferece uma "compreensão consistente do regime abrangente da legislação internacional de direitos humanos e sua aplicação a questões de orientação sexual e identidade de gênero" (PRINCÍPIOS DE YOGYAKARTA, 2017, p. 8), detalhando e clarificando as obrigações estatais internacionais em direitos humanos sem discriminação homofóbica.

\subsection{Os direitos humanos LGBTIs no sistema interamericano de direitos humanos}

O Sistema Interamericano de Direitos Humanos (SIDH), comparado ao sistema universal, exibe maior clareza no reconhecimento dos direitos humanos LGBTIs. Aqui anotam-se, de modo explícito, a vigência de instrumentos normativos e a atuação decidida de órgãos protetivos, como a Comissão Interamericana de Direitos Humanos (CIDH) e a Corte Interamericana de Direitos Humanos. (CORTE IDH). ${ }^{9}$ Diante dos limites deste artigo, arrolam-se dois

\footnotetext{
Trata-se da declaração de violação do Pacto Internacional de Direitos Civis e Políticos, pelo Estado da Austrália, do direito à privacidade, pela criminalização de atos sexuais consensuais entre pessoas adultas de mesmo sexo. Ver ONU (2005, p. 133).

8 Conforme referências em ONU (2011b, p. 3): "'The United Nations Speaks Out: Tackling Discrimination on Grounds of Sexual Orientation and Gender Identity', OHCHR, WHO and Unaids, April 2011; the statements made by the United Nations High Commissioner for Human Rights at a side event of the fifteenth session of the Human Rights Council, on the theme, 'Ending violence and criminal sanctions based on sexual orientation and gender identity', 17 September 2010; remarks made at the conclusion of the interactive dialogue with the High Commissioner at the sixteenth session of the Human Rights Council, 3 March 2011; 'Legal environments, human rights and HIV responses among men who have sex with men and transgender people in Asia and the Pacific: an agenda for action', UNDP, July 2010; 'Protecting children from violence in sport: a review with a focus on industrialized countries', Unicef, July, 2010; 'International technical guidance on sexuality education', Unesco with Unaids, Unfpa, Unicef and WHO, December 2009; UNHCR, Guidance Note on Refugee Claims Relating to Sexual Orientation and Gender Identity, UNHCR, November 2008; Report of the Director-General: Equality at Work, ILO, 2007; Report on prevention and treatment of HIV and other sexually-transmitted infections among men who have sex with men and transgender populations, WHO, June 2011; 'Experiencias de estigma y discriminación en personas homosexuales/gays, bisexuales y trans', Unfpa, July 2010; International Guidelines on HIV/AIDS and Human Rights, Unaids and OHCHR, July 2006".

9 Para um panorama da proteção dos direitos LGBTIs no SIDH, ver RIOS et al. (2017). Ver também VECCHIATTI; VIANNA (2014).
} 
marcos de grande relevância em virtude de sua ampla aplicabilidade na região: a Convenção Interamericana contra toda Forma de Discriminação e de Intolerância (OEA, 2013) e a Opinião Consultiva n. 24 da Corte IDH (CORTE IDH, 2017).

Com efeito, com a promulgação da Convenção Interamericana contra Toda Forma de Discriminação e Intolerância (OEA, 2013), foram explicitados, em um instrumento com alta densidade jurídica ("hard law"), vários critérios proibidos de discriminação, dentre os quais destacam-se "sexo, orientação sexual, identidade e expressão de gênero" (artigo 1, item 1). A partir de então, a proteção antidiscriminatória, propiciada pelo SIDH, tem, dentre seus destinatários, literalmente, pessoas e grupos LGBTIs, em reforço à previsão aberta e exemplificativa até então disponível (RIOS; SOUZA; SPONCHIADO, 2014).

Tal enumeração ganha ainda mais força à luz da Opinião Consultiva n. 24, de 2017 (OC 24/2017 - CORTE IDH, 2017), proferida pela Corte IDH a partir de requerimento da Costa Rica sobre

Identidade de Gênero, Igualdade e Não Discriminação a casais do mesmo sexo - obrigações estatais em relação à mudança de nome, à identidade de gênero e aos direitos derivados de um vínculo entre casais do mesmo sexo (interpretação e alcance dos artigos 1.1, 3으, 7으, 11.2, 13, 17, 18 e 24, em relação ao artigo 1ㅇ da Convenção Americana sobre Direitos Humanos) (CORTE IDH, 2017, p. 1).

Trata-se de manifestação ampla da Corte IDH, tendo em mente toda disposição sobre direitos humanos de qualquer tratado aplicável nos estados americanos (CORTE IDH, 2017, parágrafo 17), procedimento “...de grande importância para os países da região na medida em que permitirá precisar as obrigações estatais em relação aos direitos das pessoas LGBTIs no marco das obrigações de respeitar e garantir os direitos humanos a toda pessoa sob sua jurisdição" (CORTE IDH, 2017, parágrafo 21).

$\mathrm{Na}$ OC 24/17 estão positivados conceitos operativos, tais como sexo, sexo designado ao nascimento, sistema binário sexo/gênero, intersexualidade, gênero, identidade de gênero, expressão de gênero, transgênero, pessoa trans, pessoa transexual, pessoa travesti, pessoa cisgênero, orientação sexual, homossexualidade, pessoa heterossexual, lésbica, gay, homofobia e transfobia, lesbofobia, bissexual, cisnormatividade e heteronormatividade, sempre levando em conta o estado da arte sobre tais conceitos no debate internacional (CORTE IDH, 2017 Parte IV, item A). A presença de lista exemplificativa desse teor, por si só, faz ver o alcance e a utilidade desta manifestação consultiva, contribuindo, ao mesmo tempo, para a efetividade do SIDH e para a atividade dos órgãos do sistema de justiça nacionais.

Para finalizar esta notícia panorâmica sobre o estado da arte dos direitos LGBTIs nos sistemas de proteção de direitos humanos universal e interamericano, apresenta-se mais que oportuno o informe "Avances y desafíos hacia el reconocimiento de los derechos de las personas LGBTIs en las Américas", de 2018, apresentado pela CIDH (CIDH, 2018). Além de alertar para a pouca efetividade de muitas medidas estatais e para a precariedade dos registros da violência contra pessoas LGBTIs, a CIDH reafirmou os standards de proteção no SIDH, que podem ser assim indicados: 


\section{Democracia}

(1) ênfase no direito a não discriminação, à igualdade perante a lei, o direito à vida e à integridade pessoal como fundantes dos sistemas regional e universal dos direitos humanos, acarretando aos Estados deveres jurídicos que se revestem de especial importância para as pessoas LGBTIs;

(2) acento no dever dos Estados de atuar com a devida diligência para prevenir, investigar, sancionar e reparar também as violações à autonomia, identidade e dignidade;

(3) o compromisso dos Estados em respeitar e garantir os direitos humanos sem discriminação por raça, sexo, cor, idioma, religião, opiniões políticas ou de qualquer outra índole, origem nacional ou social, posição econômica, nascimento ou qualquer outra condição social;

(4) afirmação, pela CDH, a partir do caso Atala Riffo vs. Chile, de que Osig são categorias protegidas pelo artigo 1.1. da Convenção Interamericana de Direitos Humanos, sendo qualquer diferença de tratamento fundada nesses critérios considerada suspeita, presumivelmente incompatível com a Convenção;

(5) proteção de discriminação também com base na expressão de gênero, abarcada desde o artigo 1.1. da Convenção.

(6) inclusão da garantia dos direitos econômicos, sociais e culturais no âmbito da proteção antidiscriminatória de pessoas LGBTIs, alcançando, por exemplo, direito à seguridade social, à saúde e ao trabalho.

Apresentados os elementos fundamentais para a compreensão e aplicação dos direitos LGBTIs como direitos humanos universais, importa refletir sobre a tarefa dos sistemas de justiça nacionais na concretização dos direitos fundamentais e no exercício de suas tarefas institucionais.

\section{OS DIREITOS HUMANOS LGBTIS E OS SISTEMAS DE JUSTIÇA NACIONAIS}

A afirmação dos direitos humanos LGBTIs e dos respectivos standards de proteção, expressam não somente princípios de justiça diante de situações de violência e discriminação; eles também contribuem para o aperfeiçoamento do direito e do sistema de justiça nacionais, informando tanto o conteúdo e a interpretação de cada ordenamento jurídico interno quanto indicando rumos para as instituições e os agentes do Poder Judiciário e do Ministério Público.

\subsection{Os direitos humanos LGBTIs e os ordenamentos jurídicos nacionais}

No atual estágio do direito internacional e do direito constitucional, o conteúdo e a interpretação dos direitos fundamentais ${ }^{10}$ recebe o influxo dos direitos humanos internacionais e de sua compreensão, fenômeno que deita raízes no constitucionalismo desde a modernidade (CANOTILHO, 1993, p. 18).

\footnotetext{
${ }_{10}$ Por direitos fundamentais compreendem-se os direitos básicos previstos em favor de pessoas naturais e jurídicas na Constituição de cada país; por direitos humanos, aqueles previstos no direito internacional público, constantes nos instrumentos internacionais de direitos humanos.
} 
Assim, os ordenamentos jurídicos nacionais, quanto ao conteúdo, haverão de: (a) inspirar-se e se reforçar quando coincidirem suas disposições internas com as diretrizes do direito internacional dos direitos humanos; (b) serem complementados e integrados pelos direitos humanos previstos no direito internacional quando estes não estejam desenvolvidos internamente; e (c) intensificarem o grau de proteção dos direitos fundamentais, em virtude da primazia da norma mais benéfica de direito internacional perante a previsão interna menos generosa (PIOVESAN, 2010, p. 60).

Quanto à interpretação dos direitos fundamentais, os direitos humanos e sua compreensão pelos respectivos órgãos de monitoramento e de aplicação oferecem diretrizes substanciais (NEVES, 2014). Isso em virtude da boa-fé que preside a adesão dos Estados-Partes aos tratados internacionais (MAZZUOLI, 2003), como também ao princípio de interpretação pro homine, vigente no direito internacional dos direitos humanos e no direito constitucional. Estampado no artigo 29 da Convenção Americana de Direitos Humanos, ele informa a atividade dos sistemas de justiça nacionais, como expressamente lembrado pela Corte Interamericana de Direitos Humanos:

A Corte tem consciência de que os juízes e tribunais internos estão sujeitos ao império da lei e, por isso, são obrigados a aplicar as disposições vigentes no ordenamento jurídico. Mas quando um Estado ratifica um tratado internacional como a Convenção Americana, seus juízes, como parte do aparato estatal, também estão submetidos a ela, o que os obriga a velar para que os efeitos das disposições da Convenção não se vejam diminuídos pela aplicação de leis contrárias a seu objeto e a seu fim e que, desde o início, carecem de efeitos jurídicos. Em outras palavras, o Poder Judiciário deve exercer uma espécie de "controle de convencionalidade" entre as normas jurídicas internas aplicadas a casos concretos e a Convenção Americana sobre Direitos Humanos. Nesta tarefa, o Poder Judiciário deve levar em conta não apenas o tratado, mas também a interpretação que a Corte Interamericana, intérprete última da Convenção Americana, fez do mesmo (BRASIL, 2014, p. 96).

A observância do direito internacional dos direitos humanos na interpretação do direito interno é reconhecida no direito comparado também além das fronteiras do hemisfério americano. No direito europeu, por exemplo, Espanha, Alemanha e Reino Unido, de modo expresso em sua legislação e por obra de seus tribunais, tomam os tratados de direitos humanos e a interpretação das cortes internacionais em sua ordem jurídica (MAUÉS, 2013).

Na América Latina o quadro não é diferente. ${ }^{11}$ Argentina, Colômbia e Uruguai, dentre outros, caminham na mesma direção. De fato, o artigo 75, item 22, da Constituição da Argentina, ao conferir força constitucional a uma série de tratados internacionais de direitos humanos, não se limita a enumerar a competência para a aprovação dos tratados internacionais. A Constituição colombiana, por sua vez, é expressa ao dispor sobre a interpretação dos direitos e deveres constitucionais "em conformidade com os tratados internacionais sobre direitos humanos" (artigo 93), o que inclui a incorporação da jurisprudência dos tribunais internacionais na compreensão do "bloco de constitucionalidade" (UPRIMNY, 2005, p. 22).

\footnotetext{
${ }^{11}$ Para mais referências comparativas na América Latina, ver CARVALHO CARDINALI (2017) e RIOS (2017).
} 


\section{Humanos e \\ Democracia}

A legislação uruguaia sobre violência de gênero faz avançar a reflexão sobre os direitos humanos internacionais, sua relação com a ordem interna e os direitos LGBTIs. São eloquentes, nesse sentido, diversos dispositivos da Lei n. 19.580 de 2017, que concretizam os direitos humanos na esfera do gênero e da sexualidade, com específica consideração das pessoas LGBTIs. Dentre tantos, podem ser destacados: (artigo 1) a extensão dos direitos a mulheres trans e a diversas orientações sexuais; (artigo 3) a interpretação mais favorável e a integração conforme os valores, fins, princípios gerais de direito e disposições da Constituição e dos instrumentos internacionais, em caso de dúvida ou conflito; (artigo 5, 'c') a enumeração expressa do sexo, da orientação sexual e da identidade de gênero como critérios proibidos de discriminação; tudo sem esquecer da previsão de um amplo sistema de proteção, abrangendo direitos positivos nas arenas da educação, do trabalho e da saúde.

Como deflui desses dispositivos, o direito uruguaio coloca-se como caso exemplar do reconhecimento dos direitos LGBTIs, ao positivar e especificar exigências decorrentes do direito internacional dos direitos humanos; ${ }^{12}$ ademais, atuou de modo atento à interpretação e aplicação de direitos humanos universais, de modo integral e articulado, em benefício de indivíduos e grupos discriminados.

\subsection{Direitos humanos LGBTIs e sistema de justiça nacional}

A presença dos direitos humanos na ordem interna não se esgota no âmbito da legislação interna e de sua interpretação. Ao dispor sobre o dever de adotar disposições de direito interno, a Convenção Americana de Direitos Humanos requer também que os Estados-Partes tomem medidas "de outra natureza que forem necessárias para tornar efetivos tais direitos e liberdades" (artigo 2), o que atesta o dever de aperfeiçoar o funcionamento e a organização do sistema de justiça diante do pluralismo e da diversidade sexual.

Nesse sentido, as medidas necessárias para a efetividade dos direitos humanos LGBTIs também impelem a atuação dos sistemas de justiça nacionais, em especial ao Poder Judiciário e ao Ministério Público, dada a posição institucional que ocupam. ${ }^{13}$ No corpo do direito internacional dos direitos humanos, como também no direito interno, a estas instituições são atribuídas tarefas intransferíveis diante das violações de direitos humanos de pessoas LGBTIs. Sem adentrar nem depender da normatividade interna de cada país, basta ter presentes as manifestações do sistema internacional de direitos humanos acerca da missão e da conduta dos operadores jurídicos. É o que se conclui da leitura dos princípios e dos deveres atinentes à magistratura e aos agentes da lei, dispostos nos "Comentários aos Princípios de Bangalore de Conduta Judicial" (ONU, 2008) (daqui para frente "Bangalore"), ao lado das "Diretrizes sobre a Função dos Promotores" (ONU, 1990) (daqui para frente "Diretrizes") e do "Código de

\footnotetext{
12 Sobre as exigências normativas dos direitos humanos internacionais e os ordenamentos internos, ver FUSTER (1992, p. 56).

${ }^{13}$ A atenção aqui delimitada ao Poder Judiciário e ao Ministério Público não significa desmerecimento ou desvalorização de tantas outras frentes institucionais responsáveis pela instituição dos direitos humanos. Sem esquecer de órgãos e comissões executivas e legislativas de toda ordem, anota-se, por sua pertinência às manifestações do sistema universal de direitos humanos, a previsão das "instituições nacionais de direitos humanos", órgãos de amplo alcance para a efetivação de direitos humanos internamente, de modo independente. Ver RAMOS (2014, p. 454).
} 
Conduta para os funcionários encarregados de cumprir a lei" (ONU, 1979) (daqui para frente "Código de Conduta"). Deste corpo normativo, destacam-se os princípios relativos à imparcialidade, à não-discriminação e ao dever de proteção e promoção de direitos humanos.

O compromisso com a proteção dos direitos humanos pressupõe a adesão sincera e decidida, dele decorrendo diretamente o dever de protegê-los e promovê-los. Daí que Bangalore registre o dever de manter-se informado sobre o direito internacional dos direitos humanos (item 6.4., n. 206), que as Diretrizes (itens 8 e 12) e o Código de Conduta (artigo 2) insiram, dentre as funções dos promotores e dos agentes da lei, a defesa dos direitos humanos, tudo conduzindo ao conhecimento e ao compromisso com os direitos humanos LGBTIs.

As referências a não discriminação são ainda mais explícitas. Bangalore é claro desde a seleção dos magistrados (item 10) até o dever de assegurar tratamento igualitário, livre de discriminação de toda ordem, o que inclui expressamente orientação sexual (item 183), rejeitando estereótipos e discriminação de gênero (itens 184 e 185). As Diretrizes apresentam igual preocupação antidiscriminatória na seleção dos promotores (item 2.a) e em sua atuação (item 13.a), o que se repete no Código (artigos 1 e 2). Em matéria de direitos LGBTIs, a urgência e a necessidade do mandamento antidiscriminatório aumentam diante do caminho a ser trilhado na consolidação desses direitos e da intensidade da violência contra pessoas e grupos LGBTIs.

O conhecimento e o compromisso com os direitos humanos, sem discriminações, informam um pressuposto fundamental para a legitimidade da atuação dos operadores jurídicos, qual seja, a imparcialidade no exercício de suas funções.

As diversas dimensões da imparcialidade, diante dos direitos LGBTIs, implicam e requerem: (a) a inexistência de predisposição antagônica a tais direitos humanos e fundamentais (item 57); (b) a vedação de estereótipos negativos (item 58); (c) o dever de manter a mente aberta, em especial quando houver dissonância entre suas crenças e situações em que tiver que atuar (item 60); (d) o evitar comportamentos que possam ser percebidos como expressões de parcialidade ou preconceito, tais como comentários impróprios (item 62); (e) a irrelevância de objeções fundadas na orientação sexual dos juízes em si mesma bem como a estilos de vida não conformistas na vida privada, ausentes quaisquer outros elementos que possam indicar predisposição ou preconceito (item 89 e 105); (f) o dever de não apenas reconhecer e estar familiarizado com a diversidade sexual, mas também livre de parcialidade ou preconceito baseados em razões irrelevantes (item 186); (g) o dever de prevenir e evitar que procuradores se envolvam em condutas sexistas e inapropriadas no curso do processo (item 191). No mesmo diapasão, o item 13 das Diretrizes prevê aos promotores o dever de cumprimento de suas obrigações de modo imparcial, evitando todo tipo de discriminação política, social, religiosa, racial, cultural, sexual ou de outra índole.

A incorporação de tais parâmetros nas práticas cotidianas ${ }^{14}$ dos operadores jurídicos contribui, de modo muito significativo, para a afirmação dos direitos humanos em geral, e em particular dos direitos LGBTIs. Nesse operar, estão em jogo não somente a devida observân-

\footnotetext{
${ }^{14}$ Sobre o efeito e a necessidade desse nível de incorporação, ver VILLEGAS (2014, p. 272).
} 


\section{Humanos e \\ Democracia}

cia da ética profissional de juízes e promotores, como também a indispensável superação de assimetrias de gênero e de discriminações institucionais ${ }^{15}$ que enfraquecem a legitimidade democrática ${ }^{16}$ e a fidelidade constitucional dos agentes e do sistema de justiça como um todo.

\section{CONSIDERAÇÕES FINAIS}

A legitimidade democrática de um ordenamento jurídico e a qualidade de um sistema de justiça podem ser medidas de acordo com o grau de conhecimento e de compromisso que suas instituições e integrantes têm diante dos direitos humanos universais de indivíduos e grupos discriminados. O reconhecimento e as violações de direitos humanos LGBTIs podem servir, portanto, como marcadores de onde estamos e indicadores do rumo a tomar.

Nesse contexto, os standards de proteção dos direitos humanos LGBTIs podem impulsionar as instituições jurídicas e seus integrantes a se tornarem não só tecnicamente mais competentes, mas também individual e institucionalmente mais justos. Na relação entre o direito internacional dos direitos humanos e o direito interno, apresenta-se a oportunidade para se instaurar uma espiral virtuosa, na qual a especificidade dos direitos LGBTIs serve como propulsor para a efetividade dos direitos humanos de todos e como fator de consolidação e amadurecimento democráticos para agentes e instituições dos sistemas de justiça nacionais.

\section{REFERÊNCIAS}

AÑAZCO, Y. Z. A. Ciudadanía y género. In: CULLETON, A. et al. (org.). Direitos humanos e integração latino-americana. Porto Alegre: Entrementes Editorial, 2011.

BEITZ, C. La idea de derechos humanos. Buenos Aires: Marcial Pons, 2012.

BORRILLO, D. Le droit des sexualitès. Paris: PUF, 2009.

BRASIL. Almonacid Arellano vs. Chile. In: SECRETARIA NACIONAL DE JUSTIÇA; COMISSÃO DE ANISTIA; CORTE INTERAMERICANA DE DIREITOS HUMANOS. Jurisprudência da Corte Interamericana de Direitos Humanos. Tradução Corte Interamericana de Direitos Humanos. Brasília: Ministério da Justiça, 2014. Vol. 1.

CABAL, L.; ROA, M.; LEMAITRE, J. (ed.). Cuerpo y derecho: legislación y jurisprudencia en América Latina. Bogotá: Editorial Temis, 2001.

CANOTILHO, J. J. G. Direito constitucional. 6. ed. rev. Coimbra: Almedina, 1993.

CARVALHO CARDINALI, D. Direitos LGBT e Cortes Constitucionais Latino-Americanas: uma análise da jurisprudência da Colômbia, Peru, Chile e Brasil. RFD - Revista da Faculdade de Direito da UERJ, n. 31, p. 25-68, jun. 2017. Disponível em: https://www.e-publicacoes.uerj.br/index.php/rfduerj/article/view/27325. Acesso em: 25 ago. 2020

CIDH. Comissão Interamericana de Direitos Humanos. Avances y Desafíos hacia el reconocimiento de los derechos de las personas LGBTI en las Américas. OAS/Ser. L/V/II.170. 7 dez. 2018. Disponível em: https://www.oas. org/es/cidh/prensa/comunicados/2019/126.asp. Acesso em: 25 ago. 2020.

CORTE IDH. Corte Interamericana de Direitos Humanos. Parecer Consultivo OC-24/17. Identidade de gênero, igualdade e não discriminação a casais do mesmo sexo. 24 nov. 2017. Disponível em: https://www.corteidh. or.cr/docs/opiniones/seriea_24_por.pdf. Acesso em: 25 ago. 2020.

FUSTER, B. M. V. Los derechos humanos como derechos fundamentales. Del análisis del carácter fundamental de los derechos humanos a la distinción conceptual. In: BALLESTEROS, J. (ed.). Derechos humanos: concepto, fundamentos, sujetos. Madrid: Tecnos, 1992.

HESSE, K. A força normativa da Constituição. Trad. Gilmar Ferreira Mendes. Porto Alegre: Sérgio Fabris Editor, 1991.

\footnotetext{
${ }^{15}$ Ver RIOS (2008, p. 117-153).

${ }^{16}$ Ver AÑAZCO (2011, p. 277).
} 
MAUÉS, A. M. Supralegalidade dos Tratados Internacionais de Direitos Humanos e interpretação constitucional. SUR, 18, 2013. Disponível em: https://sur.conectas.org/supralegalidade-dos-tratados-internacionais-de-direitos-humanos-e-interpretacao-constitucional/. Acesso em: 25 ago. 2020.

MAZZUOLI, V. O. Observância e aplicação dos Tratados Internacionais na Convenção de Viena sobre o Direito dos Tratados de 1969. Revista Direito e Democracia, Canoas, v. 4, n. 2, p. 407-424, 2003.

NAGAMINE, R. R. V. K. Os direitos de pessoas LGBT na ONU (2000-2016). Sex., Salud Soc. (Rio J.), Rio de Janeiro, n. 31, p. 28-56, abr. 2019. Disponível em: http://www.scielo.br/scielo.php?script=sci_arttext\&pid=S1984-64872019000100028\&lng=en\&nrm=iso. Acesso em: 25 ago. 2020.

NEVES, M. Do diálogo entre as cortes supremas e a corte internacional de direitos humanos ao transconstitucionalismo na América Latina. Revista de Informação Legislativa, v. 51, n. 201, p. 193-214, jan./mar. 2014.

OEA. Organização dos Estados Americanos. Convenção Interamericana Contra Toda Forma de Discriminação e Intolerância, de 6 de junho de 2013.

ONU. Nações Unidas. Assembleia Geral. Informe anual del Alto Comisionado de las Naciones Unidas para los Derechos Humanos e informes de la Oficina del Alto Comisionado y del Secretario General. Leyes y prácticas discriminatorias y actos de violencia cometidos contra personas por su orientación sexual e identidad de género. 17 nov. 2011. 2011b. Disponível em: https://www2.ohchr.org/english/bodies/hrcouncil/docs/19session/A. HRC.19.41_sp.pdf. Acesso em: 25 ago. 2020.

ONU. Nações Unidas. Assembleia Geral. Resolución aprobada por el Consejo de Derechos Humanos no 17/19. Derechos humanos, orientación sexual e identidad de género. 14 de julho de 2011. 2011a. Disponível em: https://undocs.org/es/A/HRC/RES/17/19. Acesso em: 25 ago. 2020.

ONU. Nações Unidas. Código de conducta para funcionarios encargados de hacer cumplir la ley. Adoptado por la Asamblea General en su resolución 34/169, de 17 de diciembre de 1979. Disponível em: https://www.ohchr.org/ sp/professionalinterest/pages/lawenforcementofficials.aspx. Acesso em: 25 ago. 2020.

ONU. Nações Unidas. Escritório contra drogas e crime (Unodc). Comentários aos Princípios de Bangalore de Conduta Judicial. Tradução Marlon da Silva Malha e Ariane Emílio Kloth. Brasília: Conselho da Justiça Federal, 2008. Disponível em: https://www.unodc.org/documents/Ipo-brazil/Topics_corruption/Publicacoes/2008_Comentarios_aos_Principios_de_Bangalore.pdf. Acesso em: 25 ago. 2020.

ONU. Nações Unidas. Guidelines on the Role of Prosecutors. Adopted by the Eighth United Nations Congress on the Prevention of Crime and the Treatment of Offenders, Havana, Cuba, 27 August to 7 September 1990. Disponível em: https://www.ohchr.org/Documents/Professionallnterest/prosecutors.pdf. Acesso em: 25 ago. 2020. ONU. Nações Unidas. Oficina do Alto Comissariado para os Direitos Humanos. Livres \& Iguais. Igualdade LGBTI: Perguntas Frequentes. 2018a. Disponível em: https://www.unfe.org/wp-content/uploads/2018/10/FAQs-PT.pdf. Acesso em: 25 ago. 2020.

ONU. Nações Unidas. Oficina do Alto Comissariado para os Direitos Humanos. Nacidos Libres E Iguales. Orientación sexual e identidad de género en las normas internacionales de derechos humanos. New York; Ginebra, 2012. Disponível em: https://acnudh.org/pt-br/nacidos-libres-e-iguales-orientacion-sexual-e-identidad-de-genero-en-las-normas-internacionales-de-derechos-humanos/. Acesso em: 25 ago. 2020.

ONU. Nações Unidas. Oficina do Alto Comissariado para os Direitos Humanos. Selected Decisions of the Human Rights Committee under the Optional Protocol, v. 5, 2005. Disponível em: https://www.ohchr.org/Documents/ Publications/SDecisionsVol5en.pdf. Acesso em: 25 ago. 2020.

ONU. Nações Unidas. Oficina do Alto Comissariado para os Direitos Humanos. Livres \& Iguais. O Direito Internacional dos Direitos Humanos e a Orientação Sexual e Identidade de Gênero. 2018b. Disponível em: https://www. unfe.org/wp-content/uploads/2018/10/International-Human-Rights-Law-PT.pdf. Acesso em: 25 ago. 2020.

PIOVESAN, F. Temas de Direitos Humanos. São Paulo: Saraiva, 2010.

PRINCÍPIOS DE YOGYAKARTA. Princípios sobre a aplicação da Legislação Internacional de Direitos Humanos em relação à Orientação Sexual e Identidade de Gênero. Jul. 2017. Disponível em: http://www.clam.org.br/uploads/ conteudo/principios_de_yogyakarta.pdf. Acesso em: 25 ago. 2020.

RAMOS, A. C. Curso de Direitos Humanos. São Paulo: Saraiva, 2014.

RIOS, R.R. Para um direito democrático da sexualidade. Horiz. Antropol., Porto Alegre, v. 12, n. 26, p. 71-100, dez. 2006. Disponível em: http://www.scielo.br/scielo.php?script=sci_arttext\&pid=S0104-71832006000200004\&Ing=en\&nrm=iso. Acesso em: 25 ago. 2020.

RIOS, R. R. et al. O Sistema Interamericano de Direitos Humanos e a discriminação contra pessoas LGBTTI: panorama, potencialidade e limites. Rev. Direito Práx., Rio de Janeiro, v. 8, n. 2, p. 1.545-1.576, jun. 2017. Disponível em: http://www.scielo.br/scielo.php?script=sci_arttext\&pid=S2179-89662017000201545\&lng=en\&nrm=iso. Acesso em: 25 ago. 2020. 


\section{Humanos e \\ Democracia}

RIOS, R. R. Concepciones sobre la homosexualidad en las Cortes Constitucionales latinoamericanas. Revista general de Derecho Constitucional, n. 25, 2017. Disponível em: https://www.iustel.com/v2/revistas/detalle_revista.asp?id_noticia=419407\&d=1. Acesso em: 25 ago. 2020.

RIOS, R. R. Direito da Antidiscriminação: discriminação direta, indireta e ações afirmativas. Porto Alegre: Livraria do Advogado, 2008.

RIOS, R. R.; SOUZA, L. G. O.; SPONCHIADO, T. Notícias de homofobia e proteção jurídica antidiscriminatória. In: DINIZ, D.; OLIVEIRA, R. M (org.). Notícias de homofobia no Brasil. Brasília: Letras Livres, 2014. p. 159-190.

UPRIMNY, R. El bloque de constitucionalidad en Colombia: un análisis jurisprudencial y un ensayo de sistematización doctrinal. Curso de formación de promotores/as en derechos humanos, libertad sindical y trabajo decente. Universidad Nacional, Escuela Nacional Sindical, ENS Colombia, Bogotá, 2005. Disponível em: https://www.dejusticia.org/wp-content/uploads/2017/04/fi_name_recurso_46.pdf. Acesso em: 25 ago. 2020.

VECCHIATTI, P. R. Iotti.; VIANNA, T. LGBTI e o Sistema Interamericano de Direitos Humanos: a construção da cidadania internacional arco-íris". In: SILVEIRA, V.; DIAS, J.; LOPES, A. (org.). Direito internacional e direitos humanos I. CONPEDI; UFPB. Florianópolis: Conpedi; UFPB, 2014. p. 332-361. Disponível em: http://publicadireito.com.br/ publicacao/ufpb/livro.php?gt=195http://www.publicadireito.com.br/artigos/?cod=a3f66d3a6aab9fa2. Acesso em: 25 ago. 2020.

VILLEGAS, M. G. La eficacia simbólica del derecho: sociología política del campo jurídico en América Latina. 2. ed. Bogotá: IEPI; Debate, 2014. 